\title{
THE RADIOLYTIC STUDIES OF PANIPENEM IN THE SOLID STATE
}

\author{
NATALIA ROSIAK ${ }^{1}$, JUDYTA CIELECKA-PIONTEK'ㄹ, KAROLINA KILIŃSKA', \\ ROBERT SKIBIŃSKI ${ }^{2}$, DARIA SZYMANOWSKA ${ }^{3}$, ANDRZEJ MIKLASZEWSKI', \\ KORNELIA LEWANDOWSKA ${ }^{5}$, LIDIA PIEKARA-SADY, EWA TYKARSKA $^{6}$ \\ and PRZEMYSŁAW ZALEWSKI ${ }^{*}$
}

'Department of Pharmacognosy, Poznan University of Medical Sciences, Święcickiego 4, 60-781 Poznań, Poland

${ }^{2}$ Department of Medicinal Chemistry, Medical University of Lublin, Jaczewskiego 4, 20-090 Lublin, Poland

${ }^{3}$ Department of Biotechnology and Food Microbiology, Poznan University of Life Sciences, Wojska Polskiego 48, 60-627 Poznań, Poland

${ }^{4}$ Institute of Material Science and Engineering, Poznan University of Technology, Jana Pawła II 24, 60-965 Poznań, Poland

${ }^{5}$ Institute of Molecular Physics, Polish Academy of Sciences, Smoluchowskiego 17, 60-179 Poznań, Poland

${ }^{6}$ Department of Chemical Technology of Drugs, Poznan University of Medical Sciences, Grunwaldzka 6, 60-780 Poznań, Poland

\begin{abstract}
The influence of ionizing radiation on the physicochemical properties of panipenem in the solid-state was studied. In the first part of our studies, we evaluated the possibility of applying radiosterilization to obtain sterile panipenem. Spectroscopic (FT-IR, Raman), chromatography (HPLC and HPLC-MS) and X-ray powder diffraction (XRPD) studies have shown that irradiation of panipenem with the $25 \mathrm{kGy}$, the dose required to achieve sterility, does not change the physicochemical properties of the studied compound. The antimicrobial activity of panipenem irradiated with the dose of $25 \mathrm{kGy}$ was reduced for three species. It was confirmed that the decrease in antimicrobial activity might be related to the isomerization of panipenem.
\end{abstract}

Keywords: panipenem, radiation sterilization, Q-TOF, microbiological activity, FT-IR, HPLC, EPR, XRPD, Raman

Panipenem (PNP) is one of the first carbapenem antibiotics developed in Japan. As a parenteral drug has gained widespread use in severe infections and sepsis due to its antibacterial activity against most of the Gram-positive and Gram-negative bacteria (aerobic and anaerobic) (1). Despite the high effectiveness, in the kidneys, PNP is rapidly inactivated and degraded, which leads to the loss of its properties. Precisely for this reason, during the development of commercial preparation, co-administration of panipenem with betamipron was necessary to inhibit PNP uptake into the renal tubule and prevent nephrotoxicity $(2,3)$. In the clinical treatment, both compounds are used as a powder in a 1 : 1 weight ratio to prepare an intravenous solution.
According to the European Pharmacopoeia, this pharmaceutical formulation has to meet specific requirements for preparations containing an antibiotic component and administered parenterally such as sterility (4).

Radiation sterilization seems to be the most beneficial method for drugs such as $\beta$-lactams due to its chemical instability (5-8). This approach can be used at room temperature in original primary packaging and does not require the dissolution of the drug in a solvent so that we maintain greater stability of the preparation. However, despite the positive result of the radiosterilization effect on some $\beta$-lactams, the result cannot be generalized to the other antibiotics (9-16). Ionizing radiation may different-

\footnotetext{
* Corresponding author: e-mail: pzalewski@ump.edu.pl
} 


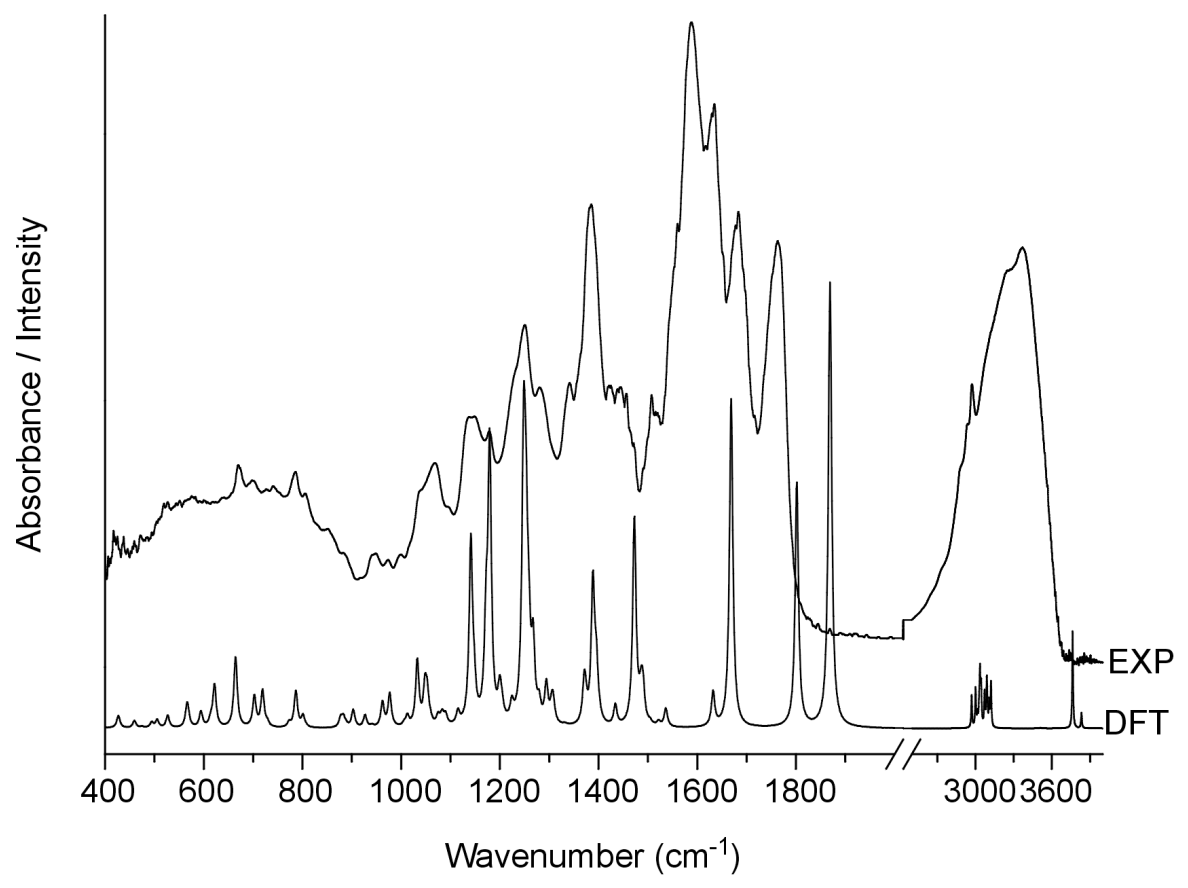

Figure 1. Calculated (DFT) and experimental (EXP) IR absorption spectra of panipenem at room temperature.

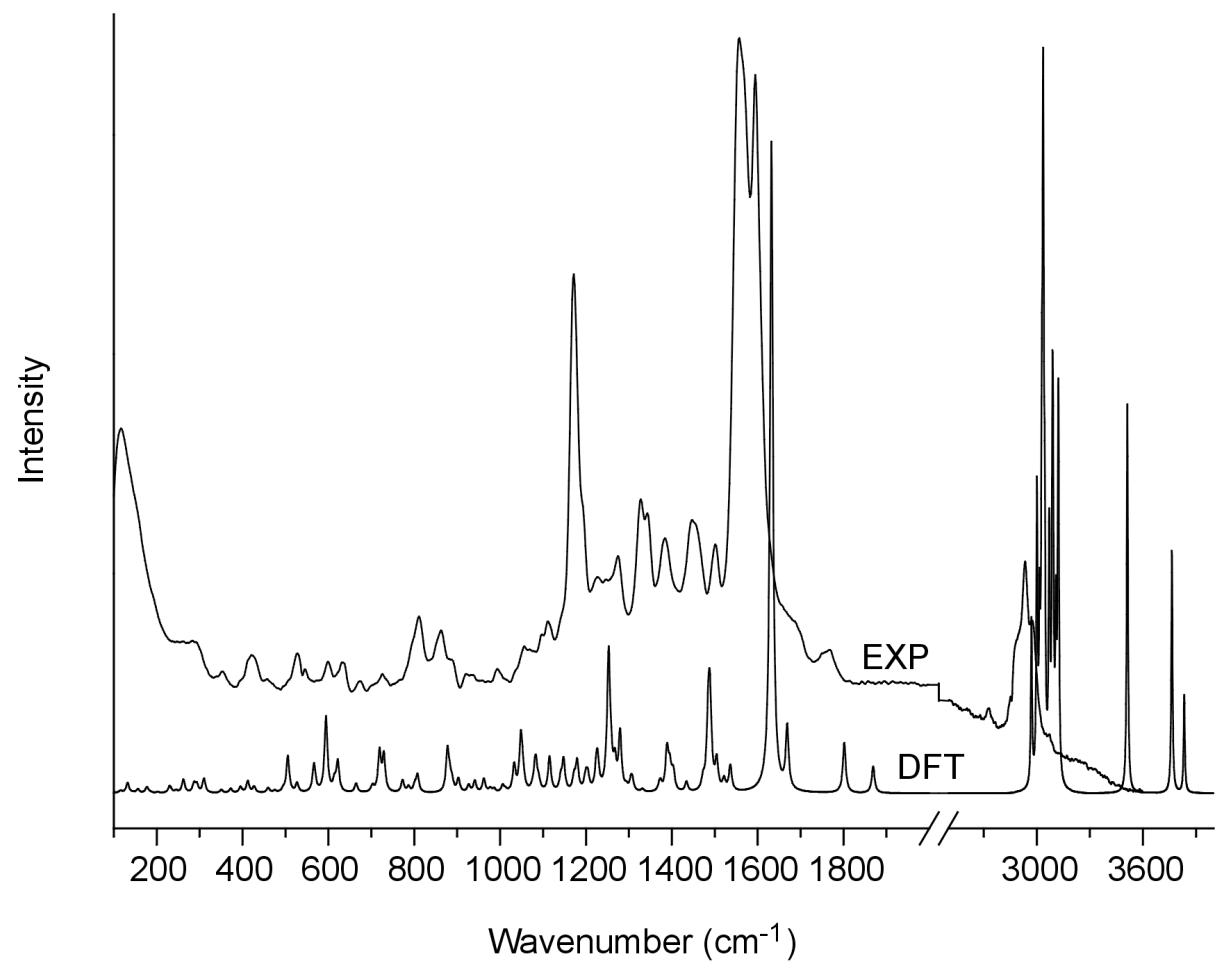

Figure 2. Calculated (DFT) and experimental (EXP) Raman scattering spectra of panipenem at room temperature. 
Table 1. Selected characteristic vibrionic features of panipenem; s-stretching, b-bending, w-wagging, r-rocking, sc-scissoring, t-twisting, def.-deformation, oop-out of plane.

\begin{tabular}{|c|c|c|c|}
\hline $\begin{array}{c}\mathrm{IR} \\
\left(\mathrm{cm}^{-1}\right)\end{array}$ & $\begin{array}{c}\text { RAMAN } \\
\left(\mathrm{cm}^{-1}\right)\end{array}$ & $\begin{array}{c}\text { DFT } \\
\left(\mathrm{cm}^{-1}\right)\end{array}$ & Bands assignment \\
\hline & 528 & 526 & Rocking pyrrolidine ring \\
\hline & 542 & 566 & $\mathrm{O}-\mathrm{H}$ oop + def $\beta$-lactam ring \\
\hline & 597 & 594 & $\mathrm{O}-\mathrm{H}$ oop + def. pyrrolidine ring \\
\hline & 633 & 621 & O-H oop \\
\hline 672 & 672 & 664 & $\mathrm{O}-\mathrm{H}$ oop + def $\beta$-lactam ring \\
\hline \multirow[t]{2}{*}{700} & & 702 & Def. oop $\beta$-lactam ring \\
\hline & 722 & 719 & $\mathrm{C}-\mathrm{O}-\mathrm{H} \mathrm{b}$ in $\mathrm{COOH}$ group + def. $\beta$-lactam ring \\
\hline 739 & & 729 & Def. pyrrolidine ring \\
\hline 785 & & 786 & $\mathrm{~N}-\mathrm{H}$ oop \\
\hline \multirow[t]{2}{*}{807} & 810 & 807 & $\mathrm{CO}_{2}$ oop + def $\beta$-lactam ring \\
\hline & 860 & 877 & Def. $\beta$-lactam ring $+\mathrm{C}-\mathrm{S} \mathrm{s}+$ def. pyrrolidine ring \\
\hline 886 & 888 & 902 & $\mathrm{C}-\mathrm{C} \mathrm{s}+\mathrm{C}-\mathrm{O} \mathrm{s}$ in $\mathrm{COOH}$ group \\
\hline 943 & 940 & 940 & $\mathrm{C}-\mathrm{C} \mathrm{s}$ in pyrrolidine ring + def. pyrrolidine ring \\
\hline 971 & & 976 & $\mathrm{C}-\mathrm{H} \mathrm{r}+$ in pyrrolidine ring $+\mathrm{C}-\mathrm{C} \mathrm{s}$ at pyrrolidine ring and $\mathrm{CH}_{3}$ group \\
\hline 999 & 993 & 1012 & $\mathrm{C}-\mathrm{N} \mathrm{s}+\mathrm{C}-\mathrm{C} \mathrm{s}$ in $\beta$-lactam ring $+\mathrm{C}-\mathrm{H} \mathrm{r}$ \\
\hline \multirow[t]{2}{*}{1039} & & 1033 & $\mathrm{C}-\mathrm{C} \mathrm{s}+\mathrm{C}-\mathrm{N} \mathrm{s}$ in $\beta$-lactam ring $+\mathrm{C}-\mathrm{O}-\mathrm{H} \mathrm{b}$ \\
\hline & 1058 & 1048 & Breathing $\beta$-lactam ring $+\mathrm{C}-\mathrm{H} \mathrm{r}+\mathrm{C}-\mathrm{N}-\mathrm{H} \mathrm{b}$ \\
\hline 1067 & & 1075 & $\mathrm{C}-\mathrm{C} \mathrm{s}+\mathrm{C}-\mathrm{N} \mathrm{s}$ in $\beta$-lactam ring $+\mathrm{C}-\mathrm{O}-\mathrm{H} \mathrm{b}$ \\
\hline \multirow[t]{2}{*}{1095} & 1098 & 1090 & $\mathrm{C}-\mathrm{H} \mathrm{r}$ at pyrrolidine ring \\
\hline & 1110 & 1115 & $\mathrm{C}-\mathrm{O} \mathrm{s}$ in $\mathrm{COH}$ group $+\mathrm{C}-\mathrm{H} \mathrm{r}$ in $\beta$-lactam ring \\
\hline 1135 & & 1141 & $\mathrm{C}-\mathrm{S} \mathrm{s}+\mathrm{C}-\mathrm{N} \mathrm{s}$ in $\beta$-lactam ring $+\mathrm{C}-\mathrm{O} \mathrm{s}$ in $\mathrm{COOH}+\mathrm{C}-\mathrm{H} \mathrm{r}$ at $\beta$-lactam ring \\
\hline 1178 & 1170 & 1179 & $\mathrm{C}-\mathrm{O} \mathrm{s}$ in $\mathrm{COOH}+\mathrm{C}-\mathrm{N} \mathrm{s}$ in $\beta$-lactam ring $+\mathrm{C}-\mathrm{O}-\mathrm{H}$ b in $\mathrm{COOH}$ group \\
\hline 1251 & & 1248 & $\mathrm{C}-\mathrm{N} \mathrm{s}$ in pyrrolidine ring $+\mathrm{C}-\mathrm{N}-\mathrm{H} \mathrm{b}+\mathrm{C}-\mathrm{H} \mathrm{t}$ at pyrrolidine ring \\
\hline 1279 & 1275 & 1279 & $\mathrm{C}-\mathrm{H} \mathrm{r}$ at pyrrolidine ring \\
\hline 1341 & 1344 & 1331 & $\mathrm{C}-\mathrm{H} \mathrm{w}$ at pyrrolidine ring \\
\hline 1386 & 1383 & 1388 & $\mathrm{C}-\mathrm{O} \mathrm{s}$ in $\mathrm{COOH}$ group $+\mathrm{C}-\mathrm{C} \mathrm{s}$ between $\beta$-lactam ring and $\mathrm{COOH}$ group \\
\hline 1445 & 1449 & 1472 & $\mathrm{C}-\mathrm{N}$ s between pyrrolidine ring and imine group \\
\hline 1457 & & 1490 & $\mathrm{C}-\mathrm{C}$ s between $\mathrm{CH}_{3}$ and $\mathrm{NH}$ \\
\hline 1505 & 1500 & 1536 & $\mathrm{C}-\mathrm{H}$ sc in $\mathrm{CH}_{2}$ at pyrrolidine ring \\
\hline 1561 & 1557 & 1632 & $\mathrm{C}=\mathrm{C} \mathrm{s}$ in $\beta$-lactam ring \\
\hline 1587 & 1593 & 1668 & $\mathrm{C}=\mathrm{N} \mathrm{s}$ \\
\hline 1632 & & 1668 & $\mathrm{C}=\mathrm{N} \mathrm{s}$ \\
\hline 1682 & 1686 & 1801 & $\mathrm{C}=\mathrm{O} \mathrm{s}$ in $\mathrm{COOH}$ group \\
\hline \multirow[t]{2}{*}{1763} & 1770 & 1869 & $\mathrm{C}=\mathrm{O} \mathrm{s}$ \\
\hline & 2940 & 3037 & $\mathrm{C}-\mathrm{H} \mathrm{s}$ in $\mathrm{CH} 3$ \\
\hline 2976 & 2976 & 3089 & $\mathrm{C}-\mathrm{H} \mathrm{s}$ at pyrrolidine ring \\
\hline 3241 & & 3511 & $\mathrm{~N}-\mathrm{H} \mathrm{s}$ \\
\hline 3369 & & 3763 & $\mathrm{O}-\mathrm{H} \mathrm{s}$ \\
\hline
\end{tabular}


ly affect the physicochemical properties of the individual compounds; therefore detailed radiolytic studies are necessary.

In this paper, we focused on the effect of ionizing radiation on panipenem. A standard recommended dose of irradiation - $25 \mathrm{kGy}$ (17) and higher radiation doses (50-400 kGy) have been applied to understand the process of potential physicochemical changes in PNP after sterilization. It should be noted that our previous investigation proves the lack of influence of irradiation at the standard dose (25 $\mathrm{kGy}$ ) on the physicochemical properties of betamipron (co-administered with panipenem); thus this method we will use for sterilization and decontamination of PNP (18).

\section{MATERIALS AND METHODS}

\section{Standards and reagents}

Panipenem was acquired from Ontario Chemicals Inc. (Ontario, Canada), as a white to offwhite powder with the purity at the level of $97 \%$, slightly soluble in DMSO and water. All other chemicals and solvents were obtained from Merck KGaA (Germany) and were of analytical grade. High-quality pure water was prepared using the Millipore purification system (Millipore, Molsheim, France, model Exil SA 67120).

\section{Irradiation}

Samples of PNP were weighted into colorless glass vials in an amount of $5 \mathrm{mg}$ and closed with plastic stoppers. All of the vials were exposed to $\beta$ irradiation in a linear electron accelerator LAE 13/9 (9.96 MeV electron beam and $6.2 \mu \mathrm{A}$ current intensity) until the doses of 25 and $400 \mathrm{kGy}$ were absorbed.

\section{Fourier Transform Infrared (FT-IR) spectroscopy}

The spectra were determined using Fourier Transform Infrared (FT-IR) spectrometer, IR Affinity-1 Shimadzu. Samples were prepared by mixing ERP with potassium bromide in proportions of 1 $\mathrm{mg}$ of sample to $300 \mathrm{mg} \mathrm{KBr}$. Pellets were formed under the pressure of $15 \mathrm{ton} / \mathrm{cm}^{2}$ with a barrel of 13 $\mathrm{mm}$ in diameter. Absorption spectra were recorded with a resolution of $2 \mathrm{~cm}^{-1}$ within a wavenumber range from 4000 to $400 \mathrm{~cm}^{-1}$ (30 scans per spectrum).

\section{Raman spectroscopy}

Raman scattering spectra were obtained with a LabRAM HR800 spectrophotometer (HORIBA Jobin Yvon) with laser excitations $\lambda$ exc $=488$ and $514 \mathrm{~nm}$ (Stabillite 2017 Ar laser) and with a laser excitation $\lambda$ exc $=633 \mathrm{~nm}$ (He-Ne laser). In each case, the power of the laser beam at the sample was less than $1 \mathrm{~mW}$ to avoid damage to the samples.

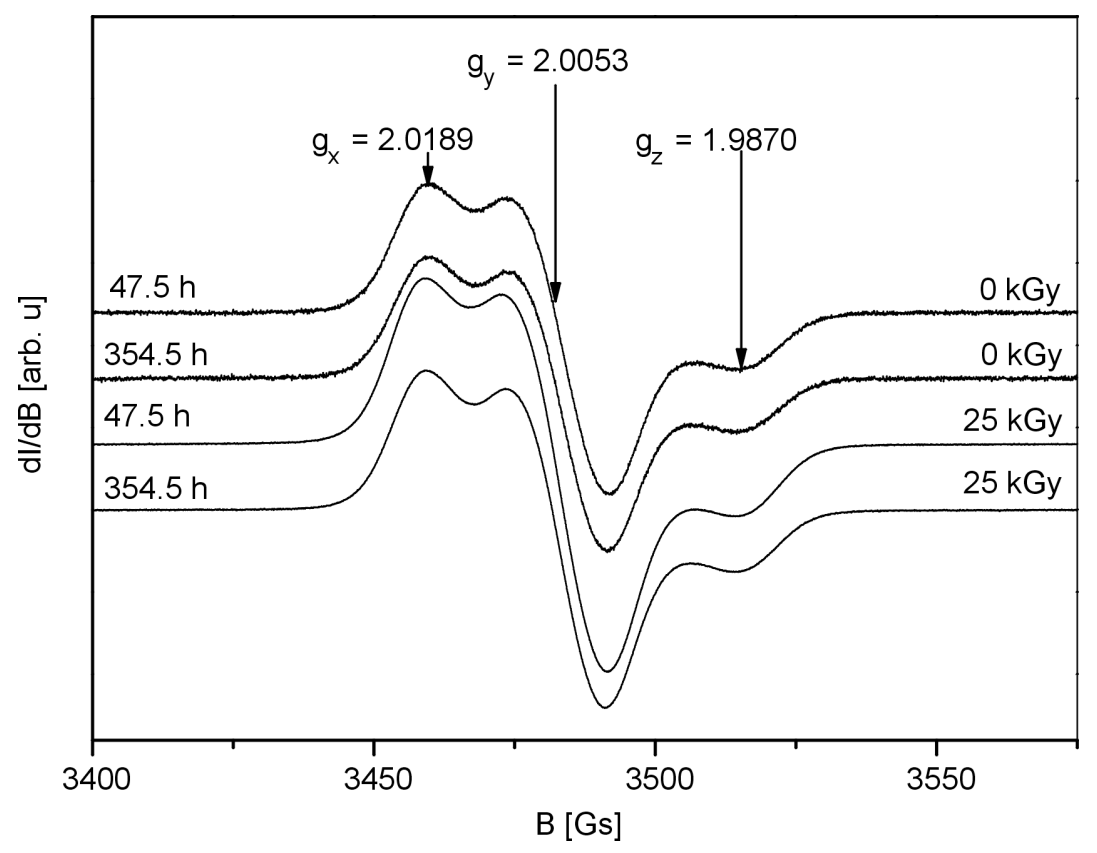

Figure 3. EPR spectra of non-irradiated ( $0 \mathrm{kGy}$ ) and irradiated (dose $25 \mathrm{kGy}$ ) PNP recorded 47.5 and $354.5 \mathrm{~h}$ after sterilization. The spectra are normalized to the mass unit of the test sample. 


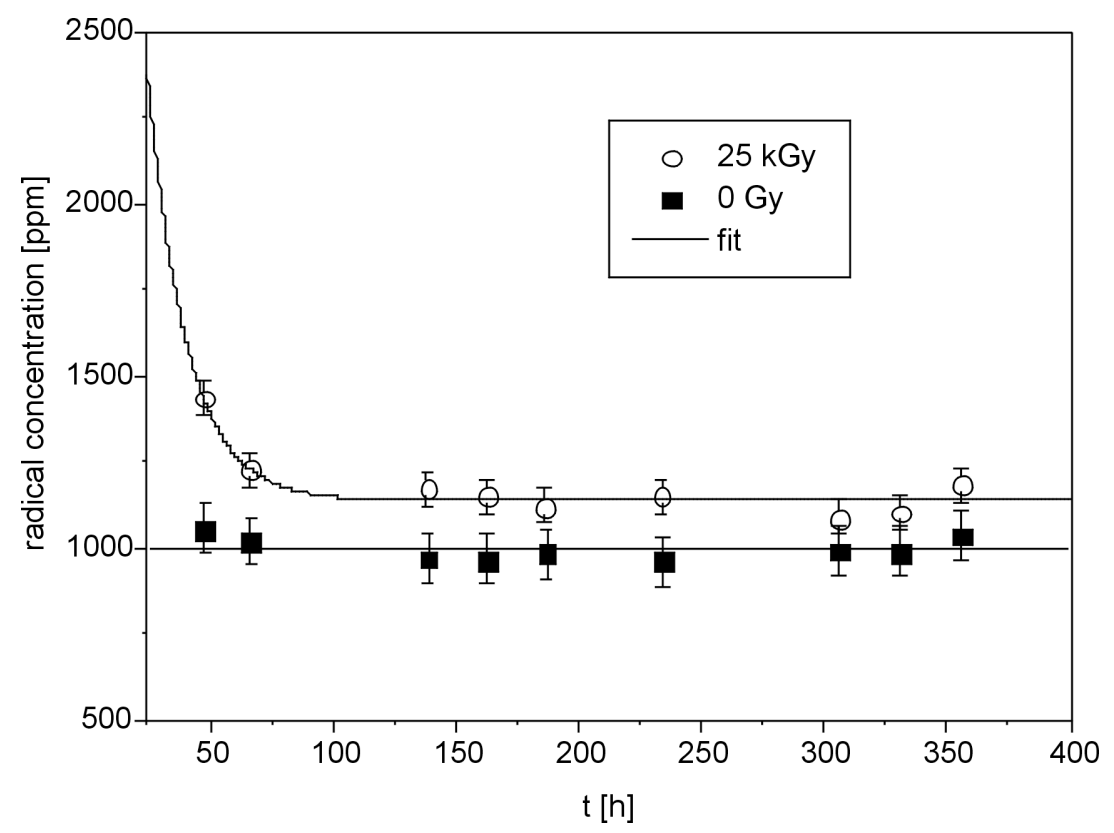

Figure 4. Concentration of radical defects for non-irradiated and irradiated (dose $25 \mathrm{kGy}$ ) PNP $v s$. time after sterilization.

Electron paramagnetic resonance (EPR) spectroscopy

The study was carried out using a Bruker ELEXSYS 500 spectrometer (Bruker, Billerica, MA, USA) to obtain the level of free radicals. The samples of PNP in the solid-state were placed in quartz capillaries (Wilmad). EPR spectra were recorded at X-band microwaves $(9.4 \mathrm{GHz})$ as a first derivative of the absorption signal. EPR experiments were performed at low microwave power $(2 \mathrm{~mW})$ and temperature $24^{\circ} \mathrm{C}$. The calculation of the free radicals level was carried out using the method described by Mai et al. (2013) (19).

\section{High-performance liquid chromatography (HPLC-DAD) analysis}

The kinetic studies of ERP samples and separation of degradation products were conducted by use of the Dionex Ultimate 3000 analytical system consisted of a quaternary pump, an autosampler, a column oven and a diode array detector (Dionex, Sunnyvale, CA, USA). The separation of degradation products was performed on Kinetex core-shell, C18, $5 \mu \mathrm{m}$ particle size, $100 \mathrm{~mm} \times 2.1 \mathrm{~mm}$ (Phenomenex, Torrance, CA, USA) and with the use of the composition of methanol and $0.05 \%$ acetic acid $(5: 95)$ as a mobile phase. $5.0 \mathrm{mg}$ of each PNP samples were dissolved in $25.0 \mathrm{~mL}$ of water, the solution so prepared was taken for HPLC analysis in injection volume $10 \mu \mathrm{L}$. The test was carried out at $298 \mathrm{~nm}$ wavelength of the diode array detector (DAD) and a temperature of $30^{\circ} \mathrm{C}$.

\section{HPLC-MS/MS analysis}

The analysis was conducted with the use of Agilent Accurate-Mass Q-TOF LC/MS G6520B system with a DESI ion source and an Infinity 1290 ultra-high-pressure liquid chromatography system consisting of a G4220A binary pump, a G1330B FC/ALS thermostat, a G4226A autosampler, a G4212A DAD and a G1316C TCC module (Agilent Technologies, Santa Clara, USA). The control of the system, data acquisition, and qualitative analysis were conducted with the use of the MassHunter workstation software B.04.00. Separations were performed on Hibar RP-18e ( $2 \mu \mathrm{m}$ particle size, $50 \mathrm{~mm}$ $\times 2.1 \mathrm{~mm}$ (Merck). The initial mobile phase composition was methanol $-0.05 \%$ acetic acid $(5: 95)$ for $2 \mathrm{~min}$. Then gradient elution was used starting from the mobile phase composition ratio $(10: 90)$ after 2 min to $50: 50$ within $10 \mathrm{~min}$ and the flow rate of the mobile phase was $0.3 \mathrm{~mL} \mathrm{~min}^{-1}$. The Q-TOF detector was tuned in the positive $(4 \mathrm{GHz})$ and the main parameters were optimized as follows: drying gas $10 \mathrm{~L} / \mathrm{min}$, nebulizer pressure 40psig, gas temp. $300^{\circ} \mathrm{C}$, capillary voltage $3500 \mathrm{~V}$, skimmer voltage $65 \mathrm{~V}$, fragmentor voltage $200 \mathrm{~V}$, octopole 1 radio frequency voltage $250 \mathrm{~V}$. The data were acquired in the 
auto MS/MS mode with the mass range $50-950 \mathrm{~m} / \mathrm{z}$ and the acquisition rate of $1.2 \mathrm{spectra} / \mathrm{s}$ (for MS and MS/MS data). The collision energy was calculated from the formula $2 \mathrm{~V}$ (slope) $*(\mathrm{~m} / \mathrm{z}) / 100+6 \mathrm{~V}$ (offset) and a maximum of 2 precursors per cycle were selected with an active exclusion mode after 1 spectrum for $0.2 \mathrm{~min}$. To ensure the accuracy of measurements, the reference mass correction was used and values 121.0508 and $922.0097 \mathrm{~m} / \mathrm{z}$ were selected as lock masses.

\section{X-ray powder diffraction (XRPD)}

X-ray powder diffraction (XRPD) patterns were obtained using the PANalitycal Empyrean system with $\mathrm{CuK} \alpha_{1}$ radiation (1.54056 $\AA$ ) at a voltage of $45 \mathrm{kV}$ and a current $40 \mathrm{~mA}$. The samples were scanned from $3^{\circ}$ to $50^{\circ} 2 \theta$ using a step size of $0.017^{\circ}$ and the scanning rate $15 \mathrm{~s} /$ step with the sample spinning.

\section{Microbiological study}

The MIC (Minimal Inhibitory Concentration) values have been determined for each reference strains from the American Type Culture Collection and clinical isolates to verify the antimicrobial activity of ERP. MICs were assayed using serial dilutions method on the Mueller-Hinton liquid medium (Merck, Germany), which follows the standards of the Clinical and Laboratory Standards Institute (CLSI) (20). In tests, microbial culture with a standardized optical density was used. The experiments for PNP samples were run in triplicate.

\section{RESULTS}

PNP identity evaluation was confirmed by spectroscopic (Fourier transform in infrared (FTIR), Raman), and X-ray powder diffraction (XRPD) studies. Figures 1 and 2 show theoretical and exper-

Table 2. MIC values $\left(\mathrm{mg} \cdot \mathrm{L}^{-1}\right)$ of unirradiated $(0 \mathrm{kGy})$ and irradiated (25 kGy, $\left.400 \mathrm{kGy}\right)$ panipenem.

\begin{tabular}{|l|c|c|c|}
\hline \multicolumn{1}{|c|}{ Microorganism } & $0 \mathrm{kGy}$ & $25 \mathrm{kGy}$ & $400 \mathrm{kGy}$ \\
\hline Pseudomonas mirabilis ATCC 12453 & 125 & 125 & 125 \\
\hline Escherichia coli ATCC 25922 & 62 & $125 \uparrow$ & 125 \\
\hline Salmonella typhimurium ATCC 14028 & 8 & $32 \uparrow$ & $62 \uparrow$ \\
\hline Acinetobacter baumanii ATCC 19606 & 125 & 125 & 125 \\
\hline Enterococcus faecalis ATTC 29212 & 125 & 125 & 250 \\
\hline Salmonella enteriditis ATCC 13076 & 32 & $125 \uparrow$ & 125 \\
\hline Enterobacter aerogenes ATCC 13048 & 125 & 125 & $250 \uparrow$ \\
\hline Pseudomonas aeruginosa ATCC 27853 & 125 & 125 & $250 \uparrow$ \\
\hline Pediococcus pentosaceus $*$ & 125 & 125 & 125 \\
\hline Staphylococcus aureus ATCC 25923 & 62 & 62 & $125 \uparrow$ \\
\hline
\end{tabular}

Table 3. Q-TOF accurate mass elemental composition and MS/MS fragmentation of the analyzed substances.

\begin{tabular}{|c|c|c|c|c|c|c|c|}
\hline Name & $\begin{array}{l}\text { Retention } \\
\text { time } \\
(\mathrm{min})\end{array}$ & $\begin{array}{c}\text { Measured } \\
\text { mass } \\
(\mathrm{m} / \mathrm{z})\end{array}$ & $\begin{array}{c}\text { Theoretical } \\
\text { mass } \\
(m / z)\end{array}$ & $\begin{array}{l}\text { Mass } \\
\text { error } \\
(\mathrm{ppm})\end{array}$ & $\begin{array}{c}\text { Molecular } \\
\text { formula } \\
{\left[\mathrm{M}+\mathrm{H}^{+}\right]}\end{array}$ & $\begin{array}{c}\text { MS/MS } \\
\text { fragmentation } \\
(\mathrm{m} / \mathrm{z})\end{array}$ & $\begin{array}{c}\text { Fragmentation } \\
\text { ions } \\
\text { formulas }\end{array}$ \\
\hline PNP & 0.6 & 340.13384 & 340.13255 & 3.79 & $\mathrm{C}_{15} \mathrm{H}_{22} \mathrm{~N}_{3} \mathrm{O}_{4} \mathrm{~S}$ & $\begin{array}{c}296.14310 \\
210.10640 \\
145.07912 \\
112.09973 \\
71.06185 \\
\end{array}$ & $\begin{array}{c}\mathrm{C}_{14} \mathrm{H}_{22} \mathrm{~N}_{3} \mathrm{O}_{2} \mathrm{~S} \\
\mathrm{C}_{10} \mathrm{H}_{16} \mathrm{~N}_{3} \mathrm{~S} \\
\mathrm{C}_{6} \mathrm{H}_{13} \mathrm{~N}_{2} \mathrm{~S} \\
\mathrm{C}_{6} \mathrm{H}_{12} \mathrm{~N}_{2} \\
\mathrm{C}_{4} \mathrm{H}_{9} \mathrm{~N}\end{array}$ \\
\hline $\mathrm{RP}$ & 0.99 & 340.13324 & 340.13255 & 2.54 & $\mathrm{C}_{15} \mathrm{H}_{22} \mathrm{~N}_{3} \mathrm{O}_{4} \mathrm{~S}$ & $\begin{array}{c}296.14332 \\
210.10686 \\
145.07885 \\
112.09935 \\
71.06277\end{array}$ & $\begin{array}{c}\mathrm{C}_{14} \mathrm{H}_{22} \mathrm{~N}_{3} \mathrm{O}_{2} \mathrm{~S} \\
\mathrm{C}_{10} \mathrm{H}_{16} \mathrm{~N}_{3} \mathrm{~S} \\
\mathrm{C}_{6} \mathrm{H}_{13} \mathrm{~N}_{2} \mathrm{~S} \\
\mathrm{C}_{6} \mathrm{H}_{12} \mathrm{~N}_{2} \\
\mathrm{C}_{4} \mathrm{H}_{9} \mathrm{~N}\end{array}$ \\
\hline
\end{tabular}


imental IR absorption and Raman scattering spectra of PNP, respectively. Theoretical calculation based on the density functional theory (DFT) approach was used to conduct a particular spectroscopic analysis in regards to all characteristic bands. The IR absorption and Raman scattering spectra of PNP are quite abundant in bands. The strongest of them are located between 1550-1800 $\mathrm{cm}^{-1}$ and are associated with the stretching vibration of the $\mathrm{C}=\mathrm{C}, \mathrm{C}=\mathrm{N}$ and $\mathrm{C}=\mathrm{O}$ bonds (Table 1 ). Medium intensity bands are located between $800-1500 \mathrm{~cm}^{-1}$. In this region, you can observe bands of both the $\beta$-lactam and pyrrolidine rings. Characteristic bands for the pyrrolidine ring are located in IR absorption and Raman scattering spectra at 943/940, 971/-, 1095/1098, 1251/-, $1279 / 1275,1341 / 1344$ and $1505 / 1500 \mathrm{~cm}^{-1}$, respectively. The first of them is corresponding to the stretching vibration of the C-C bond, and deformation of pyrrolidine ring, whereas the band at 1251 $\mathrm{cm}^{-1}$ is related to the stretching vibration of the C-N bonds. This bond has additional components related to the bending vibration of the $\mathrm{C}-\mathrm{N}-\mathrm{H}$ bonds and twisting vibration of the $\mathrm{C}-\mathrm{H}$ bonds at the pyrrolidine ring. Other of the afore-mentioned bands are associated with the rocking, wagging and scissoring vibration of the $\mathrm{C}-\mathrm{H}$ bonds at pyrrolidine ring. For $\beta$-lactam ring, besides strong band at $1561 / 1557 \mathrm{~cm}^{-1}$ (IR/Raman) related to the stretching vibration of the $\mathrm{C}=\mathrm{C}$ bond, the bands observed at 999/993, 1039/-, /1058, $1067 /-\mathrm{cm}^{-1}$ are characteristic. The first, second and fourth of them are related to the stretching vibration of the $\mathrm{C}-\mathrm{N}$ and $\mathrm{C}-\mathrm{C}$ bonds. They have additional components related to the rocking vibration of the $\mathrm{C}-\mathrm{H}$ bonds and bending vibration of the $\mathrm{C}-\mathrm{O}-\mathrm{H}$ bonds. (see Table 1). Whereas the band at $1058 \mathrm{~cm}^{-1}$ is corresponding to the breathing of the $\beta$ lactam ring and rocking vibration of the $\mathrm{C}-\mathrm{H}$ bonds and bending vibration of the $\mathrm{C}-\mathrm{O}-\mathrm{H}$ bonds. The band at $1135 \mathrm{~cm}^{-1}$ is related to the stretching vibration of the $\mathrm{C}-\mathrm{S}$ bond and stretching vibration of the $\mathrm{C}-\mathrm{N}$ bond in $\beta$-lactam ring, and stretching vibration of the $\mathrm{C}-\mathrm{O}$ bond in $\mathrm{COOH}$ group and rocking vibration of the $\mathrm{C}-\mathrm{H}$ bonds at $\beta$-lactam ring. Besides in lower frequency are observed the bands corresponding to the deformation of the $\beta$-lactam ring, e.g. 700 and $860 \mathrm{~cm}^{-1}$. In lower frequency in the Raman scattering spectrum are also located the bands associated with the out of plane vibration of the $\mathrm{O}-\mathrm{H}$ bonds, e.g. 542, 597, 633 and $672 \mathrm{~cm}^{-1}$. The bands related to the deformation vibration out of the plane of N-H and $\mathrm{CO} 2$ bond are also located at 785/- and $807 / 810 \mathrm{~cm}^{-1}$ (IR/Raman), respectively. Whereas the bands at $-/ 1110,1178 / 1170$ and $1386 / 1383 \mathrm{~cm}^{-1}$ are mainly related to the stretching vibration of the $\mathrm{C}-\mathrm{O}$ bonds in $\mathrm{COH}$ and $\mathrm{COOH}$ group, respectively. These bands are also additional components corresponding to the stretching vibration of the $\mathrm{C}-\mathrm{N}$ bond in $\beta$-lactam ring, stretching vibration of the $\mathrm{C}-\mathrm{C}$ bond between $\beta$-lactam ring and $\mathrm{COOH}$ group and bending vibration of the $\mathrm{C}-\mathrm{O}-\mathrm{H}$ bonds, (see Table 1). In the spectra, you can observe the band related to the stretching vibration of the $\mathrm{C}-\mathrm{C}$ bond between $\mathrm{CH}_{3}$ group and $\mathrm{N}-\mathrm{H}$ located at $1457 \mathrm{~cm}^{-1}$, and stretching vibration of the $\mathrm{C}-\mathrm{N}$ bond between pyrrolidine ring and amine group. Above $2500 \mathrm{~cm}^{-1}$ are located the bands related to the stretching vibration of the $\mathrm{C}-\mathrm{H}$ bonds. Above $3000 \mathrm{~cm}^{-1}$, two bands are observed at 3241 and $3369 \mathrm{~cm}^{-1}$ associated with stretching vibration of the N-H and O-H bonds.

EPR spectra of non-irradiated and irradiated (dose $25 \mathrm{kGy}$ ) PNP are presented in Figure 3. The shape of the spectra of both samples is identical, and the spectrum differs only in intensity. Thus in nonirradiated and irradiated samples, free radicals of the same type are formed, and their EPR spectra are characterized by an anisotropic spectroscopic splitting coefficient $g_{x}=2.0189( \pm 0.0007), g_{y}=2.0053$ $( \pm 0.0005), g_{z}=1.9870( \pm 0.0010)$. It should be emphasized that the radical defects are formed on the part of the molecule that is common with ertapenem, as very similar spectra are recorded in both drugs (19). The spectrum of EPR does not change over time for a non-irradiated sample (kept at room temperature), so only stable radicals (Fig. 4) occur in the sample, the concentration of which is as high as $996( \pm 33)$ ppm. Sterilization generates additional radical defects, the number of which $I(t)$ is variable over time $t$ and can be described by the following equation:

$$
I(t)=I_{s}+I_{u} e^{-t / T}
$$

where $I_{s}$ is the concentration of stable free radicals, $I_{u}$ is the concentration of unstable free radicals, and $T$ is the mean lifetime of unstable radicals. The approximation of equation 1 to the experimental points in Figure 4 gives the following parameters for the sterilized sample (dose $25 \mathrm{kGy}): I_{s}=1137( \pm 33)$ ppm, $I_{u}=5800( \pm 4500) \mathrm{ppm}, T=16.0( \pm 5.7) \mathrm{h}$.

In summary of EPR studies, we can conclude that sterilization mainly causes the generation of unstable radical defects with the short mean lifetime (16 h). High level of stable free radicals (about 1000 $\mathrm{ppm}$ ) in both irradiated and non-irradiated samples should also be underlined (25 kGy; $400 \mathrm{kGy}$ ) and non-irradiated (0 kGy) PNP samples were conducted to determine the Minimal Inhibitory Concentration (MIC) values.

The 10 bacteria strain were used - mainly Gram-negative, including clinical isolates and refer- 
ence strains (Table 2). The lowest MIC was determined for Salmonella typhimurium (reference strain $\mathrm{MIC}=8 \mathrm{mg} \cdot \mathrm{L}^{-1}$ ), and Salmonella enteriditis (reference strain $\left.\mathrm{MIC}=32 \mathrm{mg} \cdot \mathrm{L}^{-1}\right)$. The greatest MIC was established for Pseudomonas aeruginosa, Pseudomonas mirabilis, Acinetobacter baumanii, Entero- coccus faecalis, Enterobacter aerogenes (reference strain $\mathrm{MIC}=125 \mathrm{mg} \cdot \mathrm{L}^{-1}$ ) and Pediococcus pentosaceus (clinical isolate $\mathrm{MIC}=125 \mathrm{mg} \cdot \mathrm{L}^{-1}$ ). The MIC values for irradiated PNP with recommended sterilization dose (25 kGy) were at the same level as the reference sample for the majority of strains. The

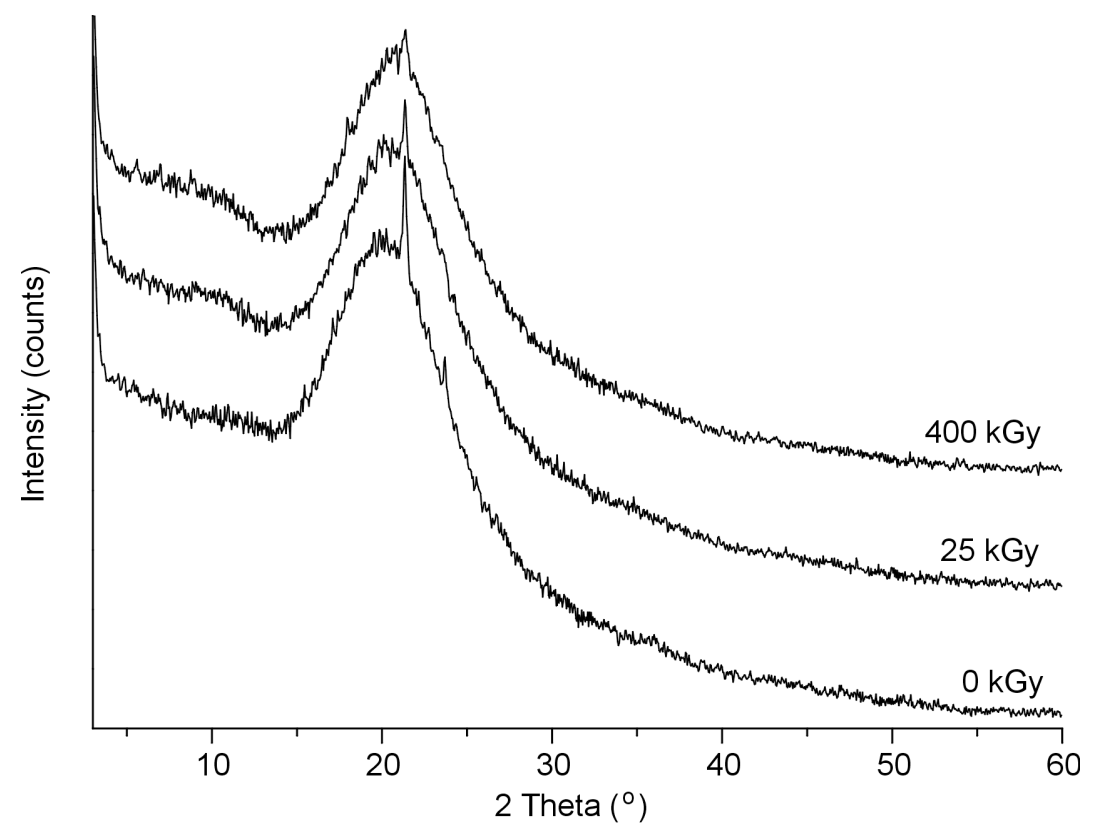

Figure 5. XRPD spectra of non-irradiated and irradiated panipenem.

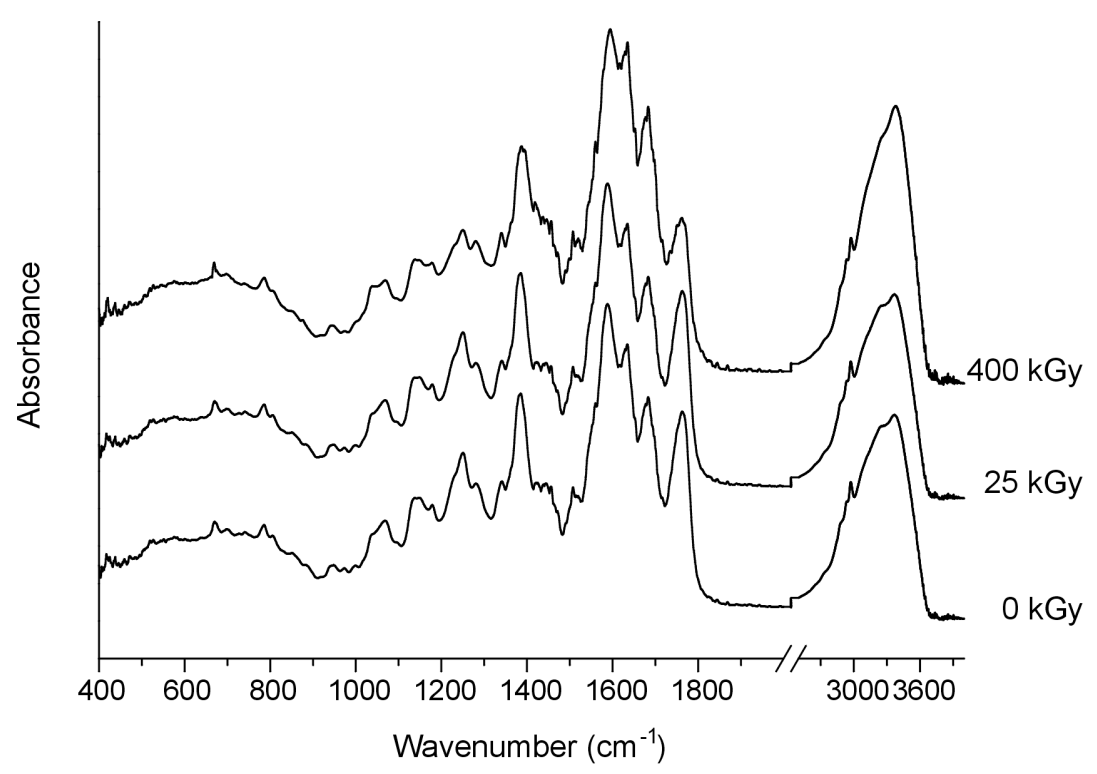

Figure 6. FT-IR spectra of unirradiated (0 kGy) and irradiated (25 kGy and $400 \mathrm{kGy})$ panipenem. 


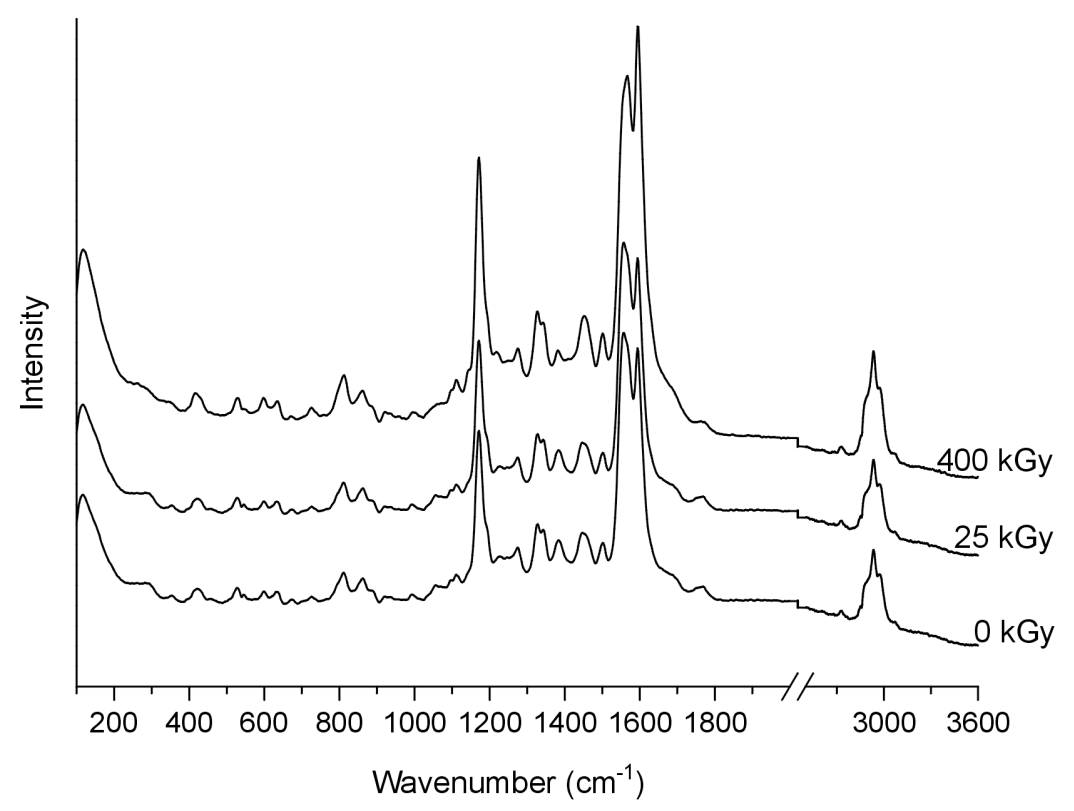

Figure 7. Raman spectra of unirradiated (0 kGy) and irradiated (25 and $400 \mathrm{kGy})$ panipenem.

value increased for 3 species - Salmonella typhimurium (MIC from $8 \mathrm{mg} \cdot \mathrm{L}^{-1} \rightarrow 32 \mathrm{mg} \cdot \mathrm{L}^{-1}$ ), Salmonella enteriditis (MIC from $32 \mathrm{mg} \cdot \mathrm{L}^{-1} \rightarrow 125$ $\mathrm{mg} \cdot \mathrm{L}^{-1}$ ), Escherichia coli (MIC from $62 \mathrm{mg} \cdot \mathrm{L}^{-1}$ $\left.\rightarrow 125 \mathrm{mg} \cdot \mathrm{L}^{-1}\right)$. The change in the effect of the active substance on the tested bacterial species was recorded in the test with sample PNP $400 \mathrm{kGy}$, increasing MIC value was observed for 7 out of 10 species. However, it should be emphasized that for three species the MIC values were unchanged $(\mathrm{MIC}=125$ $\left.\mathrm{mg} \cdot \mathrm{L}^{-1}\right)$ - Pseudomonas mirabilis, Acinetobacter baumanii and Pediococcus pentosaceus.

It can be assumed that there is a negative effect on the antimicrobial activity of panipenem irradiated with standard sterilization dose - $25 \mathrm{kGy}$, connected with some changes in the chemical structure of PNP.

The literature data confirms that the most common problem encountered after radiosterilization of solid drugs is discoloration or yellowing $(12,13,17$, 21). However, it should be emphasized that in our study, no color change of samples after exposure to radiation (25 and $400 \mathrm{kGy}$ ) was reported. These results were observed both for two different packing materials (PVP and glass containers).

XRD diffractograms (Fig. 5) indicate that nonirradiated and irradiated with a dose of $25 \mathrm{kGy}$ PNP samples are amorphous with a small fraction of the crystalline phase. The sample irradiated with a dose of $400 \mathrm{kGy}$ consists of the only amorphous phase.

Beyond identifying possible physical changes in the structure of irradiated PNP samples, its chem- ical stability was tested. HPLC-DAD analysis of irradiated samples showed a loss of content of $10 \%$ after 400 kGy irradiation.

The radiolysis product (RP) of PNP after $400 \mathrm{kGy}$ was an isomer of parent compound with identical mass and fragmentation like parent compound (Table 3).

The isomerization after radiation sterilization was previously described for cefozopran hydrochloride (10). Isomerization after irradiation for both this compound and PNP increased MIC values (decreased antibacterial activity). No changes can be seen in the IR absorption spectrum of irradiated panipenem (Fig. 6). However, in the Raman scattering spectrum a change in the intensity of two bands 1557 and 1593 $\mathrm{cm}^{-1}$ related to the stretching vibration of the $\mathrm{C}=\mathrm{C}$ and $\mathrm{C}=\mathrm{N}$ bonds is observed (Fig. 7). For unirradiated panipenem, the second band is less intense than the one recorded after radiation $400 \mathrm{kGy}$. This is probably due to the fact that before the radiation, nitrogen atom containing free electron pairs formed hydrogen bonding, which weakened the bonding strength $\mathrm{C}=$ N. Thus, its intensity was smaller.

\section{DISCUSSION}

Previous studies on the radiostability of $\beta$-lactam antibiotics have confirmed their susceptibility to degradation (7-14). Test results carried out for solid PNP reflect this statement. According to the described results, after the irradiation of the sample with a dose of $25 \mathrm{kGy}$, no significant changes in the structure of 
the compound were identified-referring to spectroscopic (FT-IR) (Fig. 6), X-ray powder diffraction (XRPD) (Fig. 5), and mass spectrometry (HPLCMS/MS) studies. Only in Raman scattering spectrum changes in the intensity of two bands (1557 and 1593 $\mathrm{cm}^{-1}$ ) were observed (Fig. 7). The antibacterial activity of PNP for 3 species was reduced (Table 2). Stability was also assessed by HPLC-DAD analysis, which showed a slight decrease in the content.

The use of a high irradiation dose (400 kGy) on PNP strongly intensified the effect of PNP degradation and allowed for the identification of degradation products by HPLC-MS/MS analysis (Table 3). The radiolysis product was an isomer of PNP. Change or changes in the structure further reduce the bactericidal properties of PNP in 4 species (Table 2). Our previous studies confirm that another compound may increase the degradation of tested antibiotic (13). It confirms the need to study each molecule separately due to its response to radiation in comparison with compounds from the same group of drugs (7-14).

\section{CONCLUSIONS}

The presented results prove that using radiation sterilization (E-beam) at a standard sterilization dose - $25 \mathrm{kGy}$ has a negative effect on the physicochemical and antimicrobial properties of panipenem and this method can not be safely used for sterilization of this compound.

\section{Acknowledgments}

This research was funded by the National Science Centre, Poland, grant number 2017/01/ $\mathrm{X} / \mathrm{NZ7/00141.}$

\section{Conflicts of interest}

The authors declare no conflict of interest.

\section{REFERENCES}

1. Kimura T., Kokubun H., Nowatari M., Matsuura N., Sunakawa K., et al.: J. Antimicrob. Chemother. 47, 51 (2001).

2. Kim S.H., Kim W.B., Kwon J.W., Lee M.G.: Biopharm. Drug Dispos. 20, 125 (1999).

3. Hikida M., Kawashima K., Yoshida M., Mitsuhashi S.J.: Antimicrob. Chemother. 30, 129 (1992).
4. European Pharmacopoeia, $9^{\text {th }}$ Edition. Strasbourg: European Directorate for the Quality of Medicines and Healthcare (EDQM), 2017.

5. Cielecka-Piontek J., Paczkowska M., Lewandowska K., Barszcz B., Zalewski P., et al.: Chem. Cent. J. 7, 98 (2013).

6. Cielecka-Piontek J., Jelińska A., Dołhań A., Zalewski P.: Int. J. Chem. Kinet. 44, 722 (2012).

7. Zalewski P., Skibiński R., Talaczyńska A., Paczkowska M., Garbacki P., et al.: J. Pharm. Biomed. Anal. 114, 222 (2015).

8. Mizera M., Talaczyńska A., Zalewski P., Skibiński R., Cielecka-Piontek J.: Talanta 137, 174 (2015).

9. Garbacki P., Zalewski P., Skibiński R., Kozak M., Ratajczak M., et al.: X-Ray Spectrom. 44, 344 (2015).

10. Zalewski P., Skibiński R., SzymanowskaPowałowska D., Piotrowska H., Kozak M., et al. J. Pharm. Biomed. Anal. 118, 410 (2016).

11. Zalewski P., Szymanowska-Powałowska D., Garbacki P., Paczkowska M., Talaczyńska A., et al.: Acta. Pol. Pharm. 72, 1253 (2015).

12. Zalewski P., Skibiński R., SzymanowskaPowałowska D., Piotrowska H., Bednarski W., et al.: Electron. J. Biotechnol. 25, 28 (2017).

13. Kilińska K., Cielecka-Piontek J., Skibiński R., Szymanowska D., Miklaszewski A., et al.: Molecules 23, 2738 (2018).

14. Kilińska K., Cielecka-Piontek J., Skibiński R., Szymanowska D., Miklaszewski A., et al.: Acta Pol. Pharm. 75, 1127 (2018).

15. Kilińska K., Cielecka-Piontek J., Skibiński R., Szymanowska D., Miklaszewski A., et al.: Acta Pol. Pharm. 76, 431 (2019).

16. Kilińska K., Cielecka-Piontek J., Skibiński R., Szymanowska D., Miklaszewski A. et al.: Molecules 24, 2944 (2019).

17. EN ISO 11137, (2006).

18. Kilińska K., Cielecka-Piontek J., Skibiński R., Szymanowska D., Miklaszewski A., et al.: Acta Pol. Pharm. 76, 629 (2019).

19. Mai V.C., Bednarski W., Borowiak-Sobkowiak B., Wilkaniec B., Samardakiewicz S., et al.: Phytochemistry 93, 49 (2013).

20. CLSI. M07-A9: Methods for Dilution Antimicrobial Susceptibility Tests for Bacteria That Grow Aerobically, Approved Standard-Ninth Edition, USA, (2012).

(C) 2020 by Polish Pharmaceutical Society. This is an open-access article under the CC BY NC license (c) (1) (9) (http://creativecommons.org/licenses/by-nc/4.0/). 